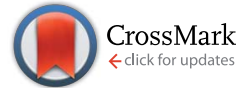

Cite this: RSC Adv., 2017, 7, 11921

\section{Preparation of magnetic mesoporous carbon from polystyrene-grafted magnetic nanoparticles for rapid extraction of chlorophenols from water samples†}

\begin{abstract}
Shan Xue, Chaozhan Wang* and Yinmao Wei
A magnetic mesoporous carbon material $\left(\mathrm{Fe}_{3} \mathrm{O}_{4} \mathrm{aC}\right)$ was fabricated by carbonizing polystyrene grafted polydopamine-coated magnetic nanoparticles. The chemical composition, morphology and magnetism of the mesoporous carbon materials were characterized. The as-prepared magnetic mesoporous carbon was employed for enrichment of chlorophenols from water samples coupled with high-performance liquid chromatography with UV detection (HPLC-UV). Various parameters affecting the enrichment were investigated. A good linearity was obtained in the range of $10-200 \mathrm{ng} \mathrm{mL}^{-1}$ for 2-CP, 4-CP and 2,4DCP, and 5-200 $\mathrm{ng} \mathrm{mL}^{-1}$ for 2,4,6-TCP. The recoveries of CPs were in the range of $84.2-120 \%$ with intra- and inter-relative standard deviations (RSD) lower than $11.0 \%$. The proposed method is fast, convenient and environmentally friendly. The results revealed the suitability of $\mathrm{Fe}_{3} \mathrm{O}_{4} @ \mathrm{C}$ nanoparticles as adsorbents for enrichment of CPs from environmental water samples.
\end{abstract}

Received 13th January 2017 Accepted 11th February 2017

DOI: $10.1039 / \mathrm{c} 7 \mathrm{ra00523g}$

rsc.li/rsc-advances materials. ${ }^{\mathbf{1 3 , 1 4}}$ Compared with traditional SPE, MSPE can greatly simplify the phase separation procedure and increase the contact areas between analytes and adsorbents, which increase the mass transfer rate and extraction equilibrium. In the MSPE procedure, the magnetic sorbent is essential, which determines the extraction efficiencies of analytes. So, the exploration of new types of the MSPE adsorbents to improve the enrichment capability for different kinds of analytes has become an active field in analytical chemistry. ${ }^{15}$

With the properties of high surface area, tunable surface chemistry, and high chemical and physical stability, ${ }^{\mathbf{1 6}}$ nanoporous carbon materials are currently finding its wide application in many fields including adsorbents, drug deliver, electrode materials, and catalyst supports. ${ }^{17-20}$ To prepare the nanoporous carbon materials, the most common and effective routes are template methods, including soft- and hardtemplate. ${ }^{21}$ There are some drawbacks with both methods. The hard-template method often involves silica as hard-template, which requires harsh chemical treatment, such as HF etch, to remove the sacrificial silica after carbonization. ${ }^{22}$ By contrast, the soft-template method which use of block copolymers as precursor, remove the template by thermal decomposition prior to carbonization. But the interactions between soft templates and carbon sources are usually too weak to prepare well-defined mesostructures. ${ }^{23}$ And both methods are complicated, expensive. ${ }^{24}$

Dopamine molecules (DA) can self-polymerize to form polydopamine (PDA) under alkaline conditions. ${ }^{25}$ Owing to the adhesion of PDA, PDA can be easily coated on the surface of
Synthetic and Natural Functional Molecule Chemistry of Ministry of Education Key Laboratory, Key Laboratory of Modern Separation Science in Shaanxi Province, College of Chemistry and Materials Science, Northwest University, 1 Xue Fu Avenue, Changan District, Xi'an 710127, Shannxi, China. E-mail: czwang@nwu.edu.cn; Fax: +86-29-81535026; Tel: +86-29-81535026

$\dagger$ Electronic supplementary information (ESI) available. See DOI: 10.1039/c7ra00523g 
substrates. Such properties can allow PDA to serve as functional layer, which contains catechol and amine function groups. This provides a route to modify the surface chemistry of materials. In addition, PDA has been proved as promising carbon precursors, owing to the nontoxic and good carbon yield. ${ }^{26}$ Surface-initiated atom transfer radical polymerization (SI-ATRP) has been explored as one of the most successful controlled/living radical polymerization techniques due to its mild reaction conditions, excellent tolerance to functional groups and impurities, and precise control on molecular weight. ${ }^{27}$ It also has been proved to be an excellent tool to introduce organic (co) polymers with precise molar mass, composition, and functionality onto nanoparticles. ${ }^{\mathbf{2 8 , 2 9}}$ Recently, organic polymer chains grafted from particles by using SI-ATRP have been used as carbon

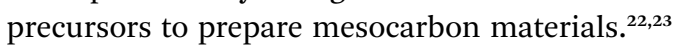

Herein, we fabricated carbon precursors by using ATRP technology to graft polystyrene from polydopamineencapsulated magnetic nanoparticles. After carbonization, the magnetic mesoporous carbon materials were obtained. The prepared magnetic carbon material was applied as adsorbent for the enrichment and analysis of chlorophenols from environmental aqueous samples.

\section{Materials and methods}

\subsection{Chemical and materials}

Anhydrous ferric chloride, anhydrous sodium acetate, trisodium citrate dihydrate, 2-chlorophenol (2-CP), 4-chlorophenol (4-CP) were obtained from Sinopharm Chemical Reagent Co., Ltd. (Shanghai, China). Dopamine hydrochloride (98\%) was purchased from Macklin Biochemical Co., Ltd. (Shanghai, China). 2-Bromoisobutyryl bromide (2-BiBB), 2,4-dichlorophenol (2,4-DCP), 2,4,6-trichlorophenol (2,4,6-TCP), copper(I) bromide $(>98 \%)$ and 2,2-bipyridyl (Bpy) (>99.5\%) were all supplied from Aladdin Chemistry Co., Ltd (Shanghai, China). Styrene (St) was obtained from Tianli Chemical Reagent Co., Ltd. (Tianjin, China), and was passed over a column of basic alumina prior to use. Acetonitrile (HPLC grade) was purchased from Fisher (USA). HPLC grade methanol and acetic acid were obtained from Kermel Chemical Reagent Co. (Tianjin, China). Other reagents were of analytical grade.

Stock solutions of CPs were prepared in methanol, with concentration levels of $1 \mathrm{mg} \mathrm{mL} \mathrm{m}^{-1}$ for each compound, and were stored in a freezer at $4{ }^{\circ} \mathrm{C}$. Working solutions were freshly diluted with $20 \mathrm{mM}$ NaAC-HAC solution at given concentrations. The tap water was collected from our laboratory, the river water from Ju River in Chang'an District, Xi'an. The water samples were stored at $4{ }^{\circ} \mathrm{C}$ and filtered using $0.45 \mu \mathrm{m}$ Nylon membranes before use.

\subsection{Instrumentation}

The Fourier-transform infrared spectrometer (FT-IR, TENSOR27, Bruker, Germany) was used to determine the functional group of nanoparticles surface. The X-ray photoelectron spectroscopy (XPS) analysis (K-Alpha Thermo Fisher Scientific) was used to determine the contents of the elements and chemical state in the nanospheres. The morphology and size were observed by scanning electron microscopy (SEM, Quanta 600FEG, America) and transmission electron microscopy (TEM, H-600, $75 \mathrm{kV}$, Hitachi, Japan). The magnetic properties were determined via a SQUID magnetometer (MPMS-XL7, Quantum Design, USA). Powder X-ray diffraction (XRD) measurements were made with $\mathrm{CuK} \alpha$ radiation on a D8 ADVANC (Bruker, Germany). Brunauer-Emmett-Teller (BET) specific surface measurements were performed using ASAP 2460 (Micromeritics, USA).

\subsection{Synthesis of $\mathrm{Fe}_{3} \mathrm{O}_{4} @ P D A$}

Magnetic $\mathrm{Fe}_{3} \mathrm{O}_{4}$ nanoparticles were prepared via solvothermal method following the reference with minor modification. ${ }^{30}$ Briefly, $1.35 \mathrm{~g}$ of $\mathrm{FeCl}_{3}$ and $0.45 \mathrm{~g}$ of trisodium citrate dehydrate were added in $30 \mathrm{~mL}$ of ethylene glycol. The mixture was heated to dissolve the solid. After cooling to room temperature, $2.40 \mathrm{~g}$ of sodium acetate was added with magnetic stirring for $30 \mathrm{~min}$. The mixture was sealed in a Teflon-lined stainless-steel autoclave. After reaction for $12 \mathrm{~h}$ at $200{ }^{\circ} \mathrm{C}$, the autoclave was cooled down to room temperature. The resulting $\mathrm{Fe}_{3} \mathrm{O}_{4}$ nanoparticles (NPs) were washed with ethanol and distilled water several times respectively, and then dried under vacuum at $45^{\circ} \mathrm{C}$.

The $\mathrm{Fe}_{3} \mathrm{O}_{4} @ P D A$ core-shell NPs were fabricated according to the literature with minor modification. ${ }^{31} 200 \mathrm{mg} \mathrm{Fe}_{3} \mathrm{O}_{4}$ was dispersed in $100 \mathrm{~mL}$ of Tris-HCl solution (10 mM, pH 8.5) under ultrasonication for $30 \mathrm{~min}$, followed by addition of dopamine hydrochloride $(200 \mathrm{mg})$. After mechanical stirring at room temperature for $24 \mathrm{~h}, \mathrm{Fe}_{3} \mathrm{O}_{4} @$ @PA NPs were collected by magnetic separation and washed with distilled water and ethanol respectively. The product was dried under vacuum.

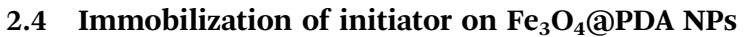

$1.0 \mathrm{~g}$ of $\mathrm{Fe}_{3} \mathrm{O}_{4} @ P D A$ NPs were dispersed in $20 \mathrm{~mL}$ of anhydrous tetrahydrofuran (THF) and sonicated for $5 \mathrm{~min}$. After stirred the mixture for $30 \mathrm{~min}$ in an ice bath, $2 \mathrm{~mL}$ of triethylamine (TEA) and $2 \mathrm{~mL}$ of 2 -BiBB were drop-wise added into the solution and maintained in an ice bath for $3 \mathrm{~h}$ under vigorous stirring. The reaction was left at $35{ }^{\circ} \mathrm{C}$ for another $12 \mathrm{~h}$. Afterwards, the obtained initiator-functionalized nanospheres, denoted as $\mathrm{Fe}_{3}$ $\mathrm{O}_{4}$ @PDA-Br, were extensively rinsed with THF, methanol and water in sequence.

\subsection{Synthesis of $\mathrm{Fe}_{3} \mathrm{O}_{4} @ P D A @ S t$ by ATRP}

$0.5 \mathrm{~g}$ of $\mathrm{Fe}_{3} \mathrm{O}_{4} @ P D A-\mathrm{Br}$ nanospheres were dispersed in a mixture of $2.4 \mathrm{~mL}$ of styrene (21 mmol), $66.5 \mathrm{mg}$ of 2,2bipyridyl $(0.42 \mathrm{mmol})$ and $10 \mathrm{~mL}$ anisole in a $50 \mathrm{~mL}$ three-neck flask. After the mixture was deoxygenated via two freeze-pumpthaw cycles, $\mathrm{CuBr}(30.5 \mathrm{mg}, 0.21 \mathrm{mmol})$ was quickly added to the flask under an nitrogen atmosphere. After two freezepump-thaw cycles, the polymerization was allowed to carry out at $90{ }^{\circ} \mathrm{C}$ for $16 \mathrm{~h}$ with continuous stirring. The resulting nanospheres were extensively washed with anisole, methanol and water in sequence. To remove the residual catalyst completely, the obtained nanoparticles were re-dispersed into a mixture of methanol and $0.25 \mathrm{M} \mathrm{EDTANa}_{2}$ solution $(1 / 1, \mathrm{v} / \mathrm{v})$, and the 
mixture was stirred at $40{ }^{\circ} \mathrm{C}$ for $4 \mathrm{~h}$. After magnetic separation, the nanoparticles was washed with water, methanol and dried at $45{ }^{\circ} \mathrm{C}$ under vacuum.

\subsection{Synthesis of $\mathrm{Fe}_{3} \mathrm{O}_{4}$ @C}

$\mathrm{Fe}_{3} \mathrm{O}_{4} @ \mathrm{C}$ was obtained by carbonizing the as-synthesized $\mathrm{Fe}_{3}$ $\mathrm{O}_{4} @ P D A @ S t$ in an $\mathrm{N}_{2}$ atmosphere. The $\mathrm{Fe}_{3} \mathrm{O}_{4} @ P D A @ S t$ NPs were heated from ambient temperature to $600{ }^{\circ} \mathrm{C}$ with a heating rate of $3{ }^{\circ} \mathrm{C} \mathrm{min}{ }^{-1}$, and was maintained at this temperature for $1 \mathrm{~h}$. The whole preparation process is shown in Fig. 1.

\subsection{MSPE procedures}

$20 \mathrm{mg}$ of $\mathrm{Fe}_{3} \mathrm{O}_{4} @ \mathrm{C}$ was added to a $20 \mathrm{~mL}$ sample solution. The mixture was shaken for $1 \mathrm{~min}$. Subsequently, the adsorbent was separated from the sample solution using a magnet, and the supernatant was discarded. Next, $0.6 \mathrm{~mL}$ of alkaline methanol was added into the centrifuge tube to elute the chlorophenols by shaking for $1 \mathrm{~min}$. The desorption solution was also separated under a magnet, then the elute solution was adjusted to neutral by $\mathrm{HCl}$.

\subsection{Analytical conditions}

The HPLC analyses were conducted on a LC-20A system from Shimadzu (Tokyo, Japan), equipped with two LC-20AD pumps, a SPD-20A ultraviolet detector, an injector with a $20 \mu \mathrm{L}$ sample loop and a CTO-20AC column oven. Chromatographic separations were performed on an Agilent TC-C18 $(150 \mathrm{~mm} \times 4.6 \mathrm{~mm}$ i.d., $5 \mu \mathrm{m}$ ) column. The mobile phase consisted of acetonitrile/ water containing $1 \%$ acetic acid $(20 / 80, \mathrm{v} / \mathrm{v}$, solvent A) and acetonitrile containing $1 \%$ acetic acid (solvent $\mathrm{B}$ ). The gradient elution program was as follows: started at $20 \%$ B and kept for $10 \mathrm{~min}$, then increased $\mathrm{B}$ to $70 \%$ in $10 \mathrm{~min}$ and kept for $5 \mathrm{~min}$. Finally the mobile phase was returned to initial condition. The

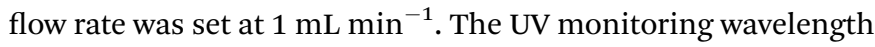
was chosen at $285 \mathrm{~nm}$ and the column oven temperature was maintained at $25^{\circ} \mathrm{C}$. The injection volume was $20 \mu \mathrm{L}$.
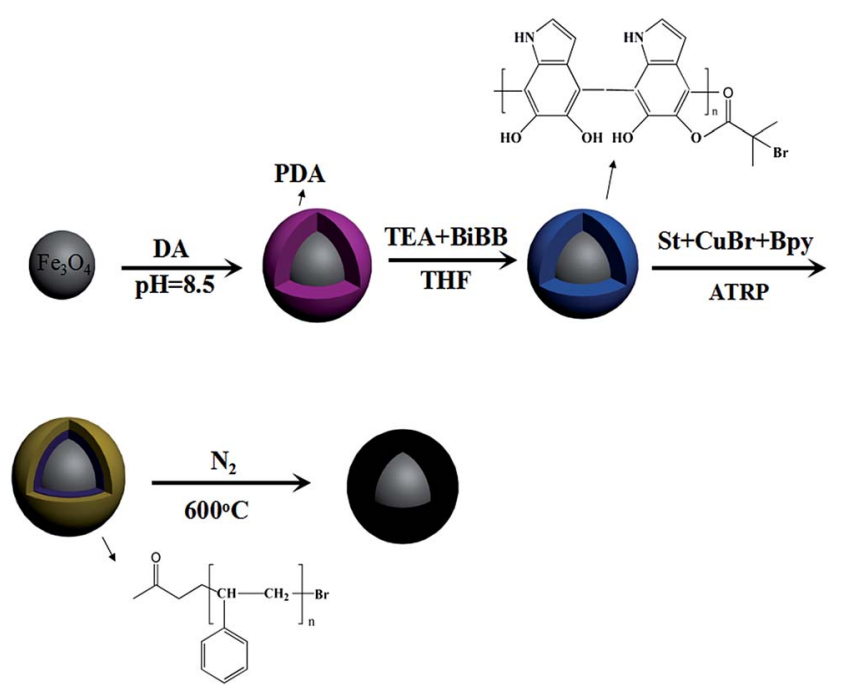

Fig. 1 Schematic illustration of the preparation of $\mathrm{Fe}_{3} \mathrm{O}_{4} \mathrm{aC}$.

\section{Results and discussion}

\subsection{Synthesis and characterizations of material}

In this study, polystyrene chains were grafted from magnetic nanoparticles via SI-ATRP, and the polymer chains were then taken as carbon resource to fabricate the $\mathrm{Fe}_{3} \mathrm{O}_{4} @ \mathrm{C}$ at a carbonization temperature of $600{ }^{\circ} \mathrm{C}$.

The morphology of the adsorbent was observed by SEM and TEM. As can be seen from the SEM (Fig. 2A) and TEM (Fig. 2C) images, the $\mathrm{Fe}_{3} \mathrm{O}_{4}$ NPs are spherical with an average diameter of $220 \mathrm{~nm}$ and have a coarse surface. The SEM (Fig. 2B) and TEM (Fig. 2D) images of $\mathrm{Fe}_{3} \mathrm{O}_{4} @ \mathrm{C}$ show that the resulting microspheres are clearly core-shell structure, with a thickness of carbon coating $\sim 40 \mathrm{~nm}$.

The functional group of $\mathrm{Fe}_{3} \mathrm{O}_{4}, \mathrm{Fe}_{3} \mathrm{O}_{4} @ P D A, \mathrm{Fe}_{3} \mathrm{O}_{4}$ @PAD@St, and $\mathrm{Fe}_{3} \mathrm{O}_{4} @ \mathrm{C}$ were investigated with FT-IR. As shown in Fig. 3A, the peak at $590 \mathrm{~cm}^{-1}$ (Fig. 3A(a-d)) is assigned to the vibration of $\mathrm{Fe}-\mathrm{O}$. Compared with $\mathrm{Fe}_{3} \mathrm{O}_{4}$ (Fig. $3 \mathrm{~A}(\mathrm{a})$ ), the IR spectrum of $\mathrm{Fe}_{3} \mathrm{O}_{4}$ @PDA (Fig. 3A(b)) shows the characteristic adsorption of the stretching of $\mathrm{C}-\mathrm{O}$ bond at $1291 \mathrm{~cm}^{-1}$, the stretching vibration of the aromatic rings at $1620 \mathrm{~cm}^{-1}$ and the $\mathrm{O}-\mathrm{H}$ stretching vibration and $\mathrm{N}-\mathrm{H}$ stretching vibration at 3380 $\mathrm{cm}^{-1}$ from PDA. After grafting St (curve $\mathrm{c}$ in Fig. 3A), new bands appeared at $1442 \mathrm{~cm}^{-1}$ and $1110 \mathrm{~cm}^{-1}$, which are ascribed to the stretching vibration of $\mathrm{C}=\mathrm{C}$ and in-plane bending vibrations of $\mathrm{C}-\mathrm{H}$ from aromatic rings. After carbonization (Fig. 3A(d)), most of the characteristic peaks of organic groups are greatly weakened, which confirm that the polymer is successfully carbonized.

Surface chemical compositions of the $\mathrm{Fe}_{3} \mathrm{O}_{4} @ \mathrm{PDA}, \mathrm{Fe}_{3^{-}}$ $\mathrm{O}_{4}$ @PDA@St, and $\mathrm{Fe}_{3} \mathrm{O}_{4} @ \mathrm{C}$ are further investigated by XPS. The survey spectrum (Fig. 3B) shows the two main peaks for $\mathrm{C} 1 \mathrm{~s}$ and $\mathrm{O} 1 \mathrm{~s}$, and the content of the each element is showed in the Table 1. From Table 1, the content of $\mathrm{C}$ element increases after carbonization, while the content of $\mathrm{O}$ element decreases. For high-resolution $\mathrm{C}$ 1s spectra of $\mathrm{Fe}_{3} \mathrm{O}_{4} @ \mathrm{C}$ in Fig. 3C, there are three peaks at around $284.4 \mathrm{eV}, 285.8 \mathrm{eV}, 289.1 \mathrm{eV}$, which are
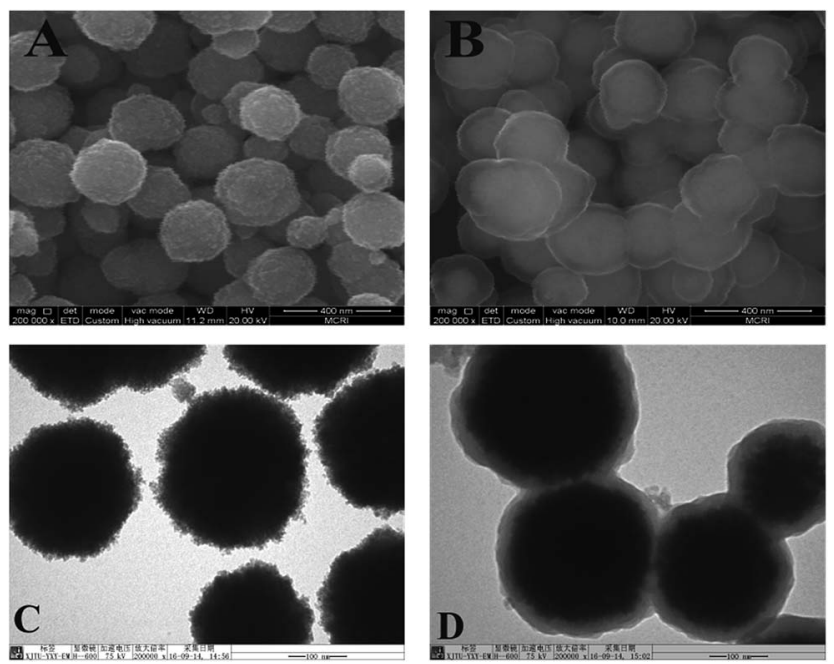

Fig. 2 SEM images of $\mathrm{Fe}_{3} \mathrm{O}_{4}(\mathrm{~A}), \mathrm{Fe}_{3} \mathrm{O}_{4} \mathrm{aC}(\mathrm{B})$; TEM images of $\mathrm{Fe}_{3} \mathrm{O}_{4}$ (C), $\mathrm{Fe}_{3} \mathrm{O}_{4} \mathrm{aC}(\mathrm{D})$. 


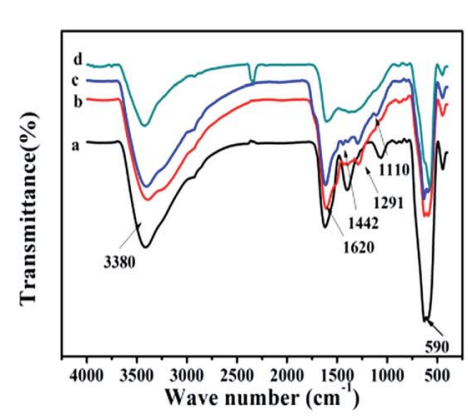

A

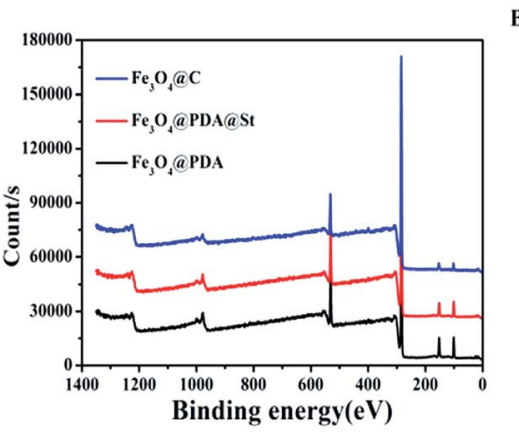

C
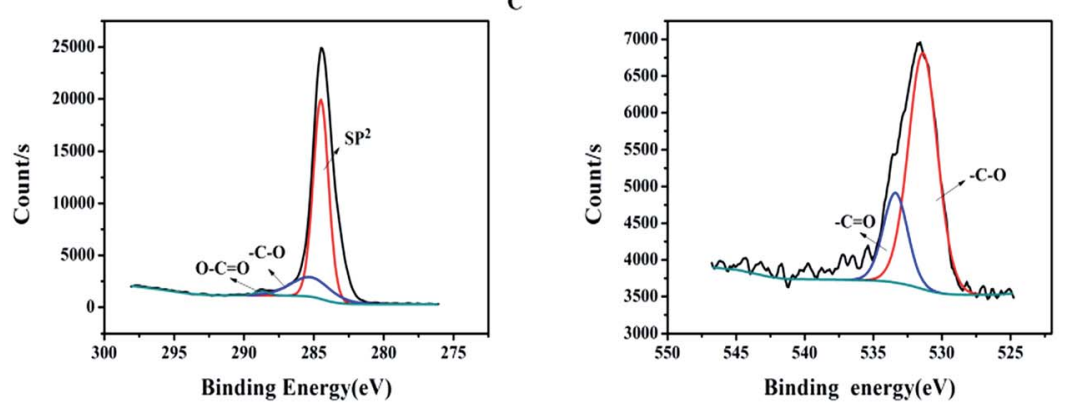

D

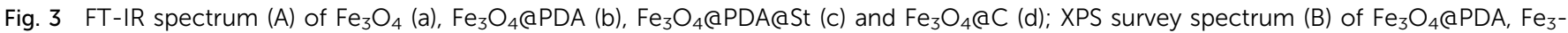
$\mathrm{O}_{4} @ P D A @ S t$, and $\mathrm{Fe}_{3} \mathrm{O}_{4} \mathrm{QC}$; high-resolution XPS spectrum of $\mathrm{C} 1 \mathrm{~s}(\mathrm{C})$, and $\mathrm{O}$ 1s (D) of $\mathrm{Fe}_{3} \mathrm{O}_{4} \mathrm{aC}$.

Table 1 Elemental content from XPS analysis

\begin{tabular}{lllc}
\hline & $\mathrm{C} 1 \mathrm{~s}($ at $\%)$ & $\mathrm{N} \mathrm{1s}($ at $\%)$ & O 1s (at\%) \\
\hline $\mathrm{Fe}_{3} \mathrm{O}_{4} @ P D A$ & 75.18 & 1.32 & 14.40 \\
$\mathrm{Fe}_{3} \mathrm{O}_{4}$ @PDA@St & 80.82 & 1.22 & 11.60 \\
$\mathrm{Fe}_{3} \mathrm{O}_{4}$ @C & 87.24 & 1.49 & 7.73
\end{tabular}

ascribed to $-\mathrm{C}=\mathrm{C},-\mathrm{C}-\mathrm{O}$ and $-\mathrm{C}=\mathrm{O}$, respectively. ${ }^{32}$ From the high-resolution XPS spectra of $\mathrm{O}$ 1s for $\mathrm{Fe}_{3} \mathrm{O}_{4} @ \mathrm{C}$ (Fig. 3D), the binding energy peak at $531.6 \mathrm{eV}$ belongs to $-\mathrm{C}-\mathrm{O}$ and the peak at $533.7 \mathrm{eV}$ belongs to $-\mathrm{C}=\mathrm{O}$ can be found..$^{33}$

The magnetic properties of $\mathrm{Fe}_{3} \mathrm{O}_{4}$ and $\mathrm{Fe}_{3} \mathrm{O}_{4} @ \mathrm{C}$ were measured via SQUID magnetometer at $300 \mathrm{~K}$ (Fig. S1A $\dagger$ ). The saturated magnetization values of $\mathrm{Fe}_{3} \mathrm{O}_{4}, \mathrm{Fe}_{3} \mathrm{O}_{4} @ \mathrm{PDA}, \mathrm{Fe}_{3}$ $\mathrm{O}_{4}$ @PDA@St and $\mathrm{Fe}_{3} \mathrm{O}_{4} @ \mathrm{C}$ are 26.7, 21.2, 18.5 and $26.5 \mathrm{emu}$ $\mathrm{g}^{-1}$, respectively. It indicated that after polydopamine coating and polystyrene grafting, the magnetism of the nanoparticles decreased gradually, and then increased after carbonization. The fact that the $\mathrm{Fe}_{3} \mathrm{O}_{4} @ \mathrm{C}$ has stronger magnetism than $\mathrm{Fe}_{3}$ $\mathrm{O}_{4} @ P D A @ S t$ maybe due to the $\mathrm{Fe}_{3} \mathrm{O}_{4} @ \mathrm{C}$ nanoparticles prepared at $600{ }^{\circ} \mathrm{C}$ exhibit ferromagnetic properties (Fig. S1A, $\dagger$ insert). ${ }^{34}$ Fig. $\mathrm{S} 1 \mathrm{~B} \dagger$ shows the XRD pattern of $\mathrm{Fe}_{3} \mathrm{O}_{4}$ and $\mathrm{Fe}_{3} \mathrm{O}_{4} @ \mathrm{C}$. All of the diffraction peaks of $\mathrm{Fe}_{3} \mathrm{O}_{4} @ \mathrm{C}$ are the same as $\mathrm{Fe}_{3} \mathrm{O}_{4}$, indicting that no new phase formed during the subsequent modification process.

The nitrogen adsorption/desorption isotherm (77 K) and pore size distribution curve (Fig. $\mathrm{S} 2 \dagger$ ) indicate that the BET surface area of $\mathrm{Fe}_{3} \mathrm{O}_{4} @ \mathrm{C}$ is $8.78 \mathrm{~m}^{2} \mathrm{~g}^{-1}$; the pore volume is $0.0171 \mathrm{~cm}^{3} \mathrm{~g}^{-1}$ and the pore size is $7.73 \mathrm{~nm}$. The adsorption/ desorption isotherms are type $\mathrm{IV}^{35}$ with $\mathrm{H} 4$ hysteresis loops, which indicate the carbon materials is mesoporous.

\subsection{Optimization of MSPE conditions}

The prepared magnetic carbon materials were then employed as an adsorbent for enrichment of four chlorophenols (2-CP, 4-CP, 2,4-DCP and 2,4,6-TCP). Principally, hydrophobic interactions and $\pi-\pi$ interactions should be involved during adsorption. To achieve the maximal extraction efficiency, several important parameters, such as solution $\mathrm{pH}$, type and volume of elution solvent, amounts of adsorbent, salt concentration, adsorption time and elution time were optimized.

3.2.1 Effect of $\mathbf{p H}$. The $\mathrm{pH}$ value is a key factory in the extraction process because it affects the existing form of target analytes. In this study, the $\mathrm{pH}$ values of sample solution (3.09.0) were tested. As shown in Fig. 4A, the extraction efficiencies for all four CPs were increased slightly when the $\mathrm{pH}$ values were increased from 3.0 to 5.0. And then declined when the $\mathrm{pH}$ values was further increased. The reason for this can be explained as follows. The chlorophenols are acidic compounds, and the existing form of the CPs in low $\mathrm{pH}$ values is molecule form, while in high $\mathrm{pH}$ values the existing form of CPs is ionic form. On one hand, the $\mathrm{Fe}_{3} \mathrm{O}_{4} @ \mathrm{C}$ is a hydrophobic material, which has a high affinity toward the chlorophenols in their molecule forms. One the other hand, the surface of $\mathrm{Fe}_{3} \mathrm{O}_{4} @ \mathrm{C}$ has negative charge with the increase of the $\mathrm{pH}$ values. ${ }^{36}$ As the result of electrostatic repulsion, the interactions between the adsorbent and analytes are greatly weakened. Finally, the solution $\mathrm{pH}$ at 5.0 was chosen for subsequent experiments.

3.2.2 Effect of salt concentration. In order to study the effect of the ionic strength on the extraction efficiency, a variable amount of $\mathrm{NaCl}[0 \%$ to $20 \%(\mathrm{w} / \mathrm{v})]$ was added to the sample solution. As shown in Fig. S3, $\uparrow$ the best extraction efficiency could be attained at $10 \% \mathrm{NaCl}$. The reason can be explained 


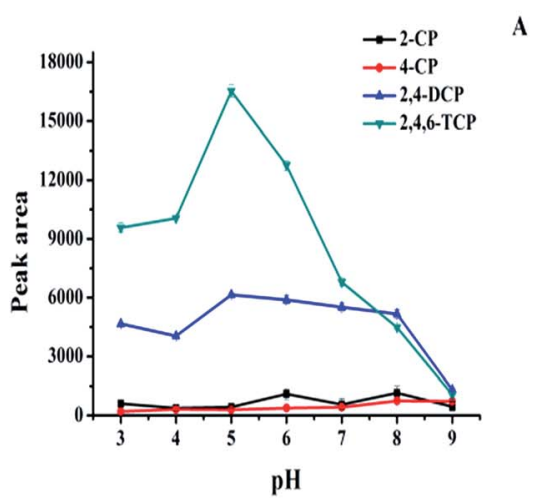

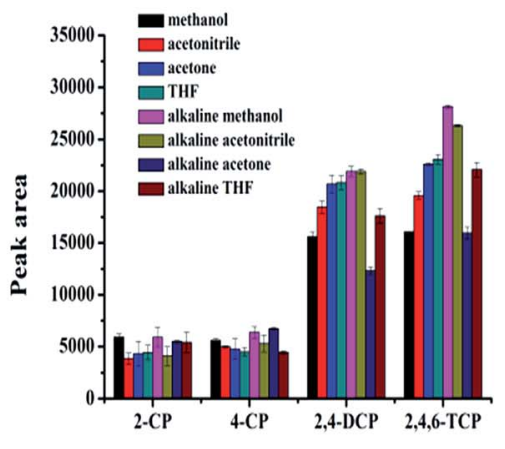

Fig. 4 Effect of several parameters for adsorption of chlorophenols. Sample solution pH (A); desorption solvents (B); CPs concentrations are all at $1.0 \mu \mathrm{g} \mathrm{mL}^{-1}$. Sample volume, $10 \mathrm{~mL}$; amount of adsorbent, $5 \mathrm{mg}$.

that the addition of $\mathrm{NaCl}$ could reduce the solubility of chlorophenols and then improve the extraction efficiency. Thus, $10 \%$ $(\mathrm{m} / \mathrm{v}) \mathrm{NaCl}$ was added in sample solution for the extraction of target chlorophenols.

3.2.3 Effect of type of desorption solution. To ensure the effective desorption of the chlorophenols analytes from sorbent, in this work, eight kinds of solvents were investigated as desorption solution, including pure methanol, acetonitrile, acetone, THF, and alkaline methanol, alkaline acetonitrile, alkaline acetone, alkaline THF. All the volume of elution solutions was fixed at $1 \mathrm{~mL}$. The results showed that the best desorption efficiency was achieved when alkaline methanol was used (Fig. 4B), which could be attributed to that in alkaline conditions, the chlorophenols could be converted into ionized form and the ionized chlorophenols would have weakened affinity to the adsorbent. Therefore alkaline methanol was used to elute the four CPs.

3.2.4 Effect of extraction time and desorption time. The effect of extraction time (Fig. S4A $\dagger$ ) was investigated in the range of 1-60 min. The results showed that the extraction efficiencies for 2-CP and 4-CP kept almost unchanged. However, the extraction efficiencies for 2,4-DCP and 2,4,6-TCP were decreased with the time increase from 1 to $30 \mathrm{~min}$, and remained constant after that. The reason for this may be attributed to the competing mass-transfer process of the analytes. ${ }^{37}$ Thus, the extraction time was $1 \mathrm{~min}$. Desorption time was also studied. The obtained results were shown in Fig. S4B, $\uparrow$ it can be found that $1 \mathrm{~min}$ was enough to elute all CPs.

3.2.5 Effect of the adsorbent amount. The adsorbent amount had a significant effect on extraction efficiency. In this work, the effect of adsorbent amounts was investigated in the range of 2-30 mg. The results shown in Fig. 5A indicated that the extraction efficiencies of the four CPs increased with the increase of the adsorbent dosage from 2 to $20 \mathrm{mg}$, and then remained almost unchanged with the further increase of the amount of the adsorbent. Hence, $20 \mathrm{mg}$ of $\mathrm{Fe}_{3} \mathrm{O}_{4} @ \mathrm{C}$ was employed in the following experiment.

3.2.6 Effect of the volume of elution solution. The volume of desorption solution was optimized in the range of 0.2 to 1.0 $\mathrm{mL}$. As shown in Fig. 5B, relatively good elution results could be achieved when $0.6 \mathrm{~mL}$ of desorption solvent was used.

\subsection{Validations of the method}

Under the optimal experimental conditions, the linearity, limit of detection (LOD) and limit of quotation (LOQ) were evaluated. All the parallel experiments were repeated three times and the
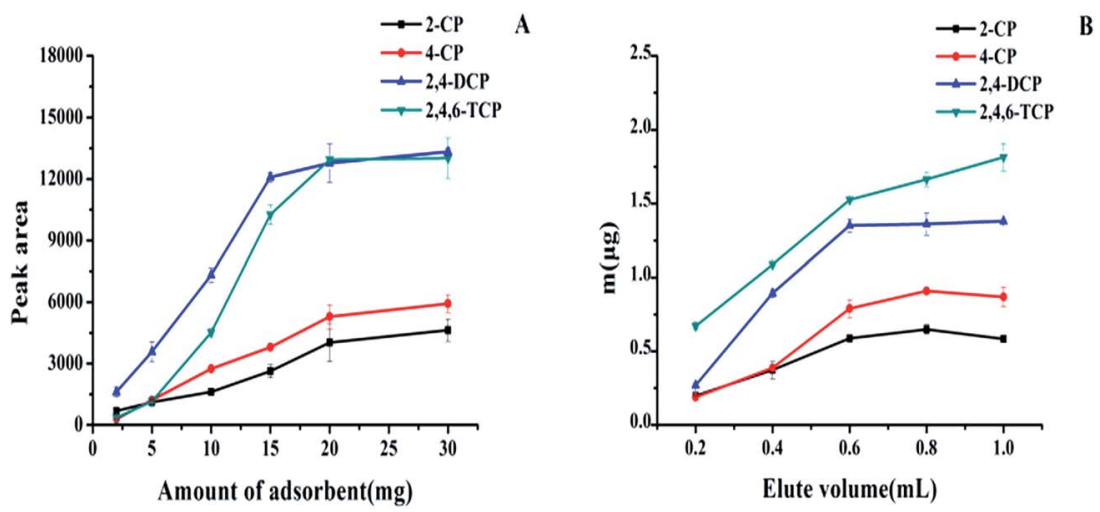

Fig. 5 Effect of the amount of adsorbent (A) and volume of elution solution (B) on the extraction of CPs. CPs concentrations are all at $200 \mathrm{ng}$ $\mathrm{mL}^{-1}$. Salt concentration, $10 \%(\mathrm{~m} / \mathrm{v}) ; \mathrm{pH}$ values, 5; extraction and desorption time, $1 \mathrm{~min}$; sample volume, $20 \mathrm{~mL}$; elution solution, alkaline methanol. 
Table 2 The linearity, LOD and LOQ of the method for the determination of CPS

\begin{tabular}{|c|c|c|c|c|c|}
\hline Analytes & Calibration curve & $r$ & Linear range $\left(\mathrm{ng} \mathrm{mL}^{-1}\right)$ & $\mathrm{LOD}\left(\mathrm{ng} \mathrm{mL}^{-1}\right)$ & $\mathrm{LOQ}\left(\mathrm{ng} \mathrm{mL}^{-1}\right)$ \\
\hline $2-\mathrm{CP}$ & $y=15.951 x+223.39$ & 0.9935 & $10-200$ & 1.41 & 4.70 \\
\hline 4-CP & $y=21.836 x+107.7$ & 0.9913 & $10-200$ & 0.88 & 2.95 \\
\hline 2,4-DCP & $y=64.155 x+775.43$ & 0.9971 & $10-200$ & 2.50 & 8.34 \\
\hline 2,4,6-TCP & $y=66.827 x+11.061$ & 0.9987 & $5-200$ & 1.32 & 4.40 \\
\hline
\end{tabular}

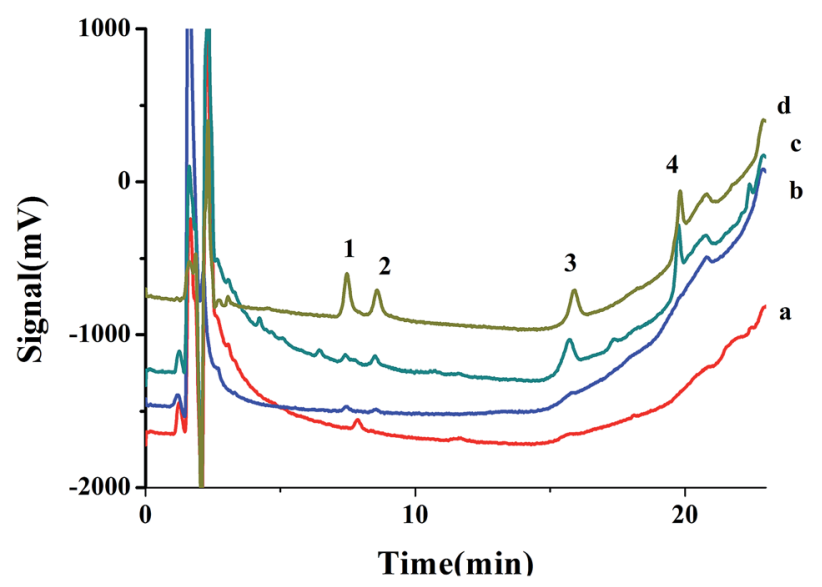

Fig. 6 Chromatograms of (a) blank river water after extraction, (b) river water spike with CPs (50 $\mathrm{ng} \mathrm{mL}^{-1}$ for each CPs), (c) river water spike with CPs at $50 \mathrm{ng} \mathrm{mL}^{-1}$ after extraction, and (d) standard solution of CPs at $500 \mathrm{ng} \mathrm{mL}^{-1}$. Peaks: (1) 2-CP, (2) 4-CP, (3) 2,4-DCP, (4) 2,4,6-TCP.

results were listed in Table 2. A good linearity was obtained in the range of $10-200 \mathrm{ng} \mathrm{mL}^{-1}$ for 2-CP, 4-CP, and 2,4-DCP, and 5-200 ng $\mathrm{mL}^{-1}$ for 2,4,6-TCP, with correlation coefficient $(r)$ ranging from 0.9913 to 0.9987 . The LODs were ranging from
$0.88-2.50 \mathrm{ng} \mathrm{mL}^{-1}\left(\mathrm{LOD}=3 S_{\mathrm{b}} / S, S_{\mathrm{b}}\right.$ is the $\mathrm{SD}$ of three replicated runs of spiked samples at the lowest concentration, $S$ is the slope of calibration curve). The LOQs were ranging from 2.95$8.34 \mathrm{ng} \mathrm{mL} \mathrm{mL}^{-1}\left(\mathrm{LOQ}=10 S_{\mathrm{b}} / S\right)$.

\subsection{Real sample analysis}

The method was applied for extraction chlorophenols from tap water and river water under optimized conditions. The chromatograms of river water sample are shown in Fig. 6. The analytical figure merits are shown in Table 3, none of four CPs was found in tap and river water. The recoveries of chlorophenols spiked at different concentration were ranging from $84.2-120 \%$ with RSDs less than $11.0 \%$, which indicated that the method is applicable for real sample analyses.

\subsection{Compare with other methods}

The comparison of different methods for the determination of CPs is displayed in Table 4. Compared with other methods, the recovery of current method is comparable, while the sample preparation time (only $2 \mathrm{~min}$ ) of the proposed method are greatly shorter than the previous method, ${ }^{6,38-41}$ which indicates that the extraction procedure is greatly fast. In addition, the

Table 3 Recovery and precision of four CPs in real water sample ${ }^{a}$

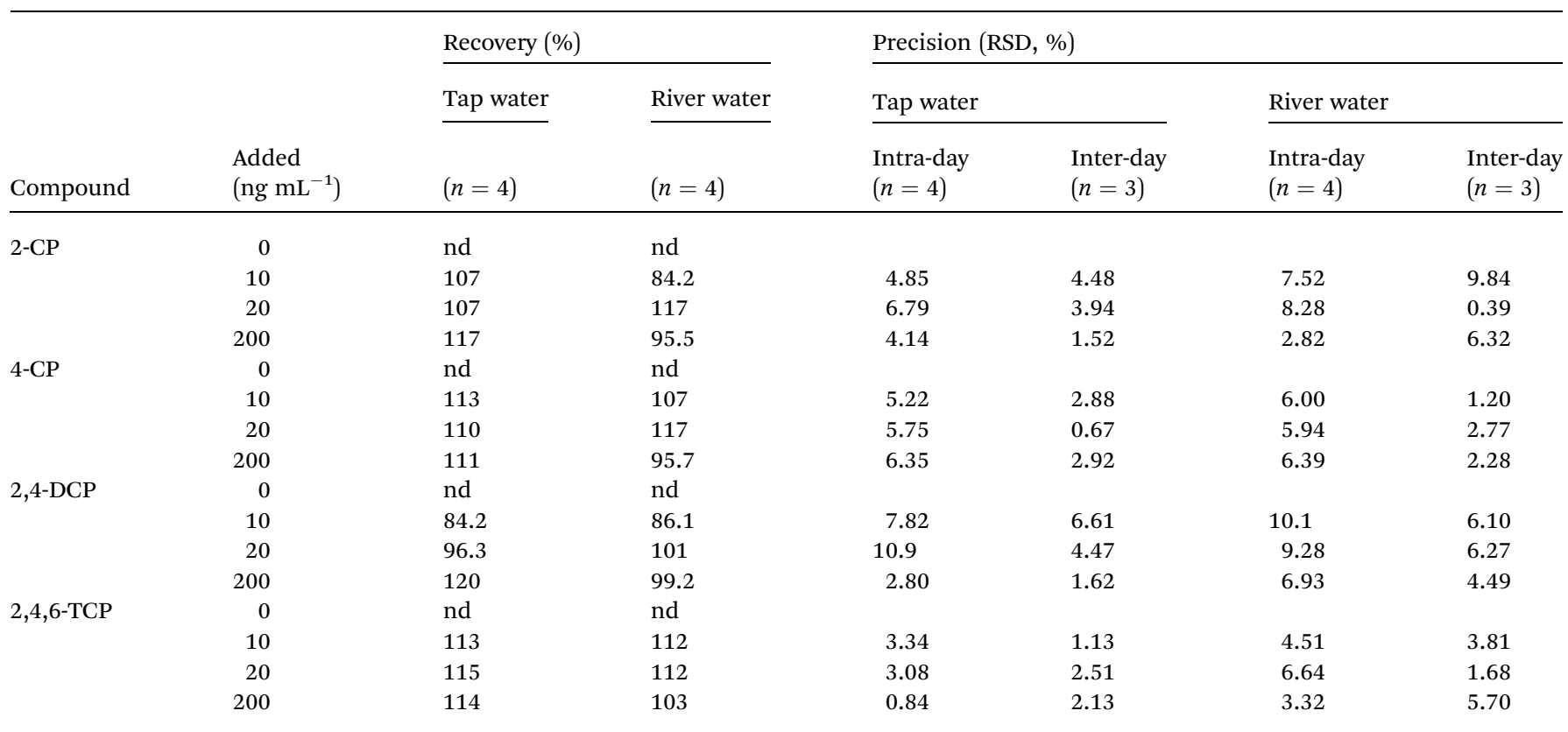

${ }^{a}$ nd: not detect. 
Table 4 Comparison of the current method with other reported method for determination of chlorophenols ${ }^{a}$

\begin{tabular}{|c|c|c|c|c|c|c|}
\hline Method & Adsorbent & $\begin{array}{l}\text { Amount of } \\
\text { sorbent (mg) }\end{array}$ & $\begin{array}{l}\text { Sample preparation } \\
\text { time (min) }\end{array}$ & $\begin{array}{l}\text { LOD } \\
\left(\mathrm{ng} \mathrm{mL}^{-1}\right)\end{array}$ & Recovery & Ref. \\
\hline MSPE-GC-MS & $\mathrm{Fe}_{3} \mathrm{O}_{4} @ \mathrm{C} @ P A N I$ & 40 & 25 & $3.22-5.55$ & $87.7-103.1$ & 38 \\
\hline SPE-HPLC-UV & Si-Ti@CN/IL & 100 & 10 & $0.83-0.95$ & 73.9-105.54 & 40 \\
\hline SPE-HPLC-UV & Cyano-functionalized MWCNT & 100 & $>67$ & $0.45-3$ & $82.53-102.13$ & 41 \\
\hline SPE-HPLC-UV & Graphene & 20 & $>35$ & $0.1-0.4$ & $77.2-116.6$ & 6 \\
\hline
\end{tabular}

${ }^{a}$ SPME: solid phase microextraction. SPE: solid phase extraction. GC-MS: gas chromatography-tandem mass spectrometry. MWCNT: multiwalled carbon nanotube.

amount of the sorbent $(20 \mathrm{mg}$ for $20 \mathrm{~mL}$ sample) is much lower than reported methods ( $40 \mathrm{mg}$ for $10 \mathrm{~mL}$ sample, ${ }^{38} 150 \mathrm{mg}$ for $80 \mathrm{~mL}$ sample,,$^{39} 100 \mathrm{mg}$ for $10 \mathrm{~mL},^{40} 100 \mathrm{mg}$ for $70 \mathrm{~mL}$ sample ${ }^{41}$ ), meaning that the adsorbent has a higher extraction capability for the CPs. Compared with other carbon materials, ${ }^{6,41}$ the as-prepared sorbent shows short sample preparation time, less adsorbent dosage, and good recovery; in addition, the as-prepared carbon possess magnetism, which makes the extraction process greatly simple, avoid the need of centrifugation or filtration. These results suggested that the proposed method is very rapid, sensitive, and convenient method to enrichment of CPs in environmental water samples.

\section{Conclusion}

In this study, magnetic mesoporous carbon materials were fabricated by carbonization of polystyrene-grafted magnetic nanoparticles. The $\mathrm{Fe}_{3} \mathrm{O}_{4} @ \mathrm{C}$ NPs were used as adsorbents to determination of chlorophenols from environmental water. The as-prepared adsorbent showed a good recovery for extraction chlorophenols from water samples because of hydrophobic interactions and $\pi-\pi$ interactions. In addition, this method not only proposed a greatly fast, convenient and simple extraction process, but was environmental friendly because of using less organic solvent. These advantages reveal that the proposed method is applicable for real water sample analysis.

\section{Acknowledgements}

This work was supported by the National Natural Science Foundation in China (No. 21575114 and 21475104) and the Scientific Research Program Funded by Shaanxi Provincial Education Department (No. 16JS114).

\section{References}

1 J. P. Wang, J. Chen, Y. F. Sun, J. T. Dai and Y. Y. Wei, Asian J. Chem., 2013, 25, 6209-6212.

2 X. Cui, W. Zuo, M. Tian, Z. Dong and J. Ma, J. Mol. Catal. A: Chem., 2016, 423, 386-392.

3 Z. Dong, X. Le, C. Dong, W. Zhang, X. Li and J. Ma, Appl. Catal., B, 2015, 162, 372-380.
4 L. Elci, N. Kolbe, S. G. Elci and J. T. Anderson, Talanta, 2011, 85, 551-555.

5 A. H. El-Sheikh, M. K. Al-Jafari and J. A. Sweileh, Int. J. Environ. Anal. Chem., 2012, 92, 190-209.

6 Q. Liu, J. Shi, L. Zeng, T. Wang, Y. Cai and G. Jiang, J. Chromatogr. A, 2011, 1218, 197-204.

7 R. Morales, L. A. Sarabia, M. Sagrario Sánchez and M. Cruz Ortiz, J. Chromatogr. A, 2013, 1296, 179-195.

8 M. Anbia, A. Haghi and S. Shariati, Anal. Methods, 2012, 4, 2555-2561.

9 X. J. Huang, Y. Zhang, M. Mei and D. X. Yuan, J. Sep. Sci., 2014, 37, 1185-1193.

10 Y. Chao, Y. Tu, Z. Jian, H. Wang and Y. Huang, J. Chromatogr. A, 2013, 1271, 41-49.

11 D. Ge and H. K. Lee, Talanta, 2015, 132, 132-136.

12 M. Ghani, M. Saraji, F. Maya and V. Cerdà, J. Chromatogr. A, 2016, 1445, 10-18.

13 G. Li, J. Lan and G. Li, RSC Adv., 2015, 5, 1705-1711.

14 L. Hao, X. L. Liu, J.-T. Wang, C. Wang, Q. H. Wu and Z. Wang, Chin. Chem. Lett., 2016, 27, 783-788.

15 S. Huo and X. Yan, Analyst, 2012, 137, 3445-3451.

16 W. Xin and Y. Song, RSC Adv., 2015, 5, 83239-83285.

17 Y. Zhao, L. Zhao, Ke X. Yao, Y. Yang, Q. Zhang and Y. Han, J. Mater. Chem., 2012, 22, 19726-19731.

18 L. Guo, H. Shi, H. Wu, Y. Zhang, X. Wang, D. Wu, L. An and S. Yang, Carbon, 2016, 107, 87-99.

19 H. Xing, F. Zhang, Y. Lu, B. Zhai, S. Zhai, Q. An and C. Yu, RSC Adv., 2016, 6, 79366-79371.

20 K. Ai, Y. Liu, C. Ruan, L. Lu and G. Lu, Adv. Mater., 2013, 25, 998-1003.

21 D. Wu, H. Dong, J. Pietrasik, E. K. Kim, C. M. Hui, M. Zhong, M. Jarnoiec, T. Kowalewsik and K. Matyjaszewski, Chem. Mater., 2011, 23, 2024-2026.

22 C. Tang, L. Bombalski, M. Kruk, M. Jaroniec, K. Matyjaszewski and T. Kowalewski, Adv. Mater., 2008, 20, 1516-1522.

23 D. Wu, Z. Li, M. Zhong, T. Kowalewski and K. Matyjaszewski, Angew. Chem., Int. Ed., 2014, 53, 3957-3960.

24 J. Zhou, Z. Zhang, Z. Li, T. Zhu and S. Zhuo, RSC Adv., 2015, 5, 46947-46954.

25 Y. Liu, K. Ai and L. Lu, Chem. Rev., 2014, 114, 5057-5115.

26 R. Liu, S. M. Mahurin, C. Li, R. R. Unocic, J. C. Idrobo, H. Gao, S. J. Pennycook and S. Dai, Angew. Chem., Int. Ed., 2011, 50, 6799-6802. 
27 Y. Zhu, F. Jiang, P. Zhang and H. Tang, Chin. Chem. Lett., 2016, 27, 910-914.

28 J. Pyun, S. Jia, T. Kowalewski, G. D. Patterson and K. Matyjaszewski, Macromolecules, 2003, 36, 5094-5104.

29 J. Pyun, K. Matyjaszewski, T. Kowalewski, D. Savin, G. Patterson, G. Kickelbick and N. Huesing, J. Am. Chem. Soc., 2001, 123, 9445-9446.

30 J. Liu, Z. Sun, Y. Deng, Y. Zou, C. Li, X. Guo, L. Xiong, Y. Gao, F. Li and D. Zhao, Angew. Chem., Int. Ed., 2009, 48, 58755879.

31 R. Liu, Y. Guo, G. Odusote, F. Qu and R. D. Priestley, ACS Appl. Mater. Interfaces, 2013, 5, 9167-9171.

32 S. Xian, F. Xu, Z. Zhao, Y. Li, Z. Li, Q. Xia, J. Xiao and H. Wang, AIChE J., 2016, 62, 3730-3738.

33 X. Wang, Y. Wu, X. Zhou, J. Xiao, Q. Xia, H. Wang and Z. Li, Chem. Eng. Sci., 2016, 155, 338-347.
34 L. Ding, M. Zhang, Y. Zhang, J. Yang, J. Zheng and J. Xu, Green Chem., 2016, 18, 6282-6290.

35 K. S. W. Sing, D. H. Everett, R. A. W. Haul, L. Moscou, R. A. Pierotti, J. Rouquérol and T. Siemieniewska, Pure Appl. Chem., 1985, 57, 603-619.

36 B. Yang, Y. Liu, Z. Li, L. Lei, X. Zhang and J. Zhou, Environ. Sci. Pollut. Res., 2016, 23, 1482-1491.

37 X. Li, A. Xue, H. Chen and S. Li, J. Chromatogr. A, 2013, 1280, 9-15.

38 J. Meng, C. Shi, B. Wei, W. Yu, C. Deng and X. Zhang, J. Chromatogr. A, 2011, 1218, 2841-2847.

39 X. Liu, J. Yin, L. Zhu, G. Zhao and H. Zhang, Talanta, 2011, 85, 2451-2457.

40 S. Bakhshaei, M. A. Kamboh, S. Mohamad, S. Md Zain and A. Ma'amor, $R S C$ Adv., 2016, 6, 49358-49369.

41 W. Gao, X. Sun, T. Chen, Y. Lin, Y. Chen, F. Lu and Z. Chen, J. Sep. Sci., 2012, 35, 1967-1976. 